tracted almost immediately; and, pressure then being applied, the contraction was kept up, and no more hæmorrhage occurred.

Case III. Hamorrhage fifleen days after Delivery. - One of the hospital midwives called me to this case fifteen days after delivery of twins. The patient had suffered great loss before my arrival, and she was still fooding freely. Examination discovered the os uteri dilated sufficiently to admit the index and middle fingers easily. A firm blood-clot was found in the uterine cavity; this was removed, and firm manual pressure was exerted over the uterus; but very slight contraction of the organ was produced. As the hæemorrhage continued, a compress was applied, the vagina was well iplugged, and the following draught prescribed every three hours.

B Liquoris secalis $m \times v$; acidi gallici gr. $v$; acidi sulph. dil. $m \times x$; aqua menthæ piperita ad そiss. $M$.

On the following day, when the plug was removed, the uterus was found to be nuch diminished in size, and the os well contracted. No more hæmorrhage followed, and the patient made a good recovery.

CASE IV. Post Partum Hicmorrhage from Irregular Contraction of the Uterus. - I was called to this case some hours after labour, which, as the midwife in attendance informed me, had been a very rapid one. I found the patient flooding violently. A bdominal and vaginal examinations proved the fundus uteri to be tolerably well contracted. At about the middle third of the uterus, there was a firm constriction; below this constriction, the organ was dilated and flaccid, with the lips of the os everted. I removed a large clot from the lower dilatation, and then forced two fingers through the constriction into the upper portion of the uterine cavity, where another clot of considerable size was found. This having been removed, the right hand was made to dilate the uterine cavity; and the uterus was then grasped abdominally by the left hand; and, the other thereby being forcibly expelled from the interior of the uterus, the organ was made to contract uniformly, and no more hæemorrhage ensued.

\section{THE CARBOLIC ACID TREATMENT.}

\section{By ALFRED FLEISCHMA N N, EsQ., M.R.C.S., Late Physician-Accoucheur's Assistant to King's College Hospital.}

To most practitioners it must have occurred, "how different is the success of the same mode of treatment in different hands !" For instance, in my own hands, hydrochlorate of ammonia in neuralgia, and oxide of silver in menorrhagia, not indiscriminately used, scarcely ever fail. Three half-drachm doses of the first, and half a dozen quarter-grain doses of the second, succeed in nine cases out of ten; and yet $I$ have been assured that others have tried them with an inverse success. Again, many modes of treatment seem to have a temporary success; and fashion in drugs, as in dress, is changeful and arbitrary.

It is a matter of surprise that Professor Lister's theory and practice of the carbolic acid treatment of wounds has engaged so little attention -a fact, I think, explained by the almost miraculous results he has ob. tained. Paradoxical as it seems, there is such a thing as failure from too great success. Most practitioners must have felt that, when a case of great danger or difficulty has been at once overcome, patients are apt to doubt if these elements ever existed, and think that the surgeon has exaggerated the case, to unduly enhance his own reputation. If Mr. Lister had been a little less successful, more attention would probably have been directed to his method. When we hear of a penetrating wound of the thorax, extending through the diaphragm into the cavity of the abdomen, through which the omentum finds its way externally, and we learn that in a few days the man, without an untoward sympton, returns safe and sound to his trade of bullock-driving, either we read one of the greatest improvements in surgical treatment that the century has yet seen, or we are listening to unscrupulous exaggeration. The judicious fear which prevents men from attending to what may be the hasty proclamation of incomplete results would lead many to the second conclu. sion, did not the established reputation of the accomplished surgeon point us to the first.

1 recently have had an opportunity of putting the method to a crucial test-with what success the following brief account, I trust, will

A gentleman, aged 64, was, on the evening of the 22 nd of July last, thrown from his carriage. I found him, a few minutes after the accident, supported in a chair, terribly shaken, but fully conscious. The scalp was torn up in a large, jagged, much contused flap, from the whole of the right half of the frontal bone, and from small portions of the temporal bone of the same side. One or two minor flaps, similarly contused and torn, hung over the forehead. There was absolute loss of nearly one-third of the torn-up tissue; the exposed bone was de. nuded of its membrane, and a portion of bone of the size of a three. penny-piece was chipped ofr. Owing to the contusion, there was but little hæmorrhage.

Before taking the responsibility of depending upon special treatment, I called in consultation Dr. Rumsey, who was fully prepared to bear me out. After cleaning the wound, I swabbed it with carbolic oil, prepared by adding half an ounce of Calvert's carbolic acid to four ounces of boiled linseed-oil. The parts were placed in apposition, and the whole wound covered (and an inch beyond) with a putty made of powdered chalk and the carbolic oil. Over this paste was spread a piece of lint soaked in the same oil. Half a drachm of Battley's solution and ten drops of tincture of arnica were administered. Ice was freely swallowed, and absolute quiet enjoined. 'There was some shock, but with favourable reaction.

The next morning, I found that the night had been comfortably passed, with some little sleep. The pulse was I12. There had been abundant oozing, which had caused the parts to crack and loosen. This I repaired, and freely brushed over the lint with the oil. The pulse in the evening was 106, and there was considerable cellular serous infiltration about the eyes and cheeks.

On the morning of the third day, I saw my patient in company with Mr. Newman, who had, up to the time of the accident, been attending him for gout. The pulse was I I 2 ; the erysipelas better. There were no head-symptoms - in fact, no bad signs of any kind. There was considerable oozing of thin, bloody, but odourless discharge.

Fourth Day.-The pulse was 93. There were no bad symptoms.

Fifth Day. - I perceived for the first time a slight animal odour, but found it proceeding from an abrasion that had been overlooked. The pulse was 93 ; the secretions were correct ; the tongue clean; the appe-
tite good.

Sixth Day.-Pulse 88. Salmon and sherry were allowed for dinner. The lint was brushed over with the carbolic oil.

Seventh Day.- There was nothing but progress to record. The right hand and knee were painful from gout.

From this date, the days passed and resembled one another up to the morning of August 2nd-that is, eleven days after the accidentwhen it was decided to remove the dressings. On removing the lint and putty, which easily came away like a thin cast, I honestly confess that I was disappointed; that is, I am afraid I had, in my enthusiasm, looked for extraordinary, and found only natural, results. Perhaps nothing has more retarded progress, and hindered the fruition of great ideas, than the natural tendency to overrate; and I fear that our own profession, from its innate liberalism and noble brotherhood, is a little too apt too attribute to great discoveries attributes of which they may well be shorn. It is very certain that Professor Lister has fructified and reduced to splendid practice a well-known principle; but it is as certain that tissue already dead is dead for ever; and that absolute loss of tissue must be replaced by Nature's liberality, rather than by her necessity. So in my case; the greater flap of torn tissue was so pounded and mashed, that muscular fibre, cellular tissue, vessel, and nerve, were reduced to one homogeneous mass; and, when first seen, were already dead. Again, allowing for retraction of torn muscle, one-third of the torn tissue was absolutely lost. Hence, on pulling off the mask which hid the wound, we found this-that the dead tissue had not come to life, and that the renewal of tissue was incomplete. But we also found, though the dead tissue was two inches square, and though the bone, bared of its nutritive mesh of nerve and vessel, was still bare, that Nature had done her spiriting gently. The line of demarcation between the living and the dead was definite, and a pair of scissors finished what Nature had begun. Again, the bone, though bare of membranc, was moist; and, though to prophesy is to prejudge, I think the dura mater will do
her part, and be the alma mater of the denuded bonc. I think a mere shell of bone will die; for the rest, the suppuration was next to nothing. The unhealed edges looked the perfection of health ; and my first disappointment was, by reflection, changed to congratulation, wherein I was confirmed by my kind friend Dr. Rumsey. By his advice, which I already had anticipated, the open wound was dressed with diluted carbolate of glycerine; and, though the pulse was good, and the functions up to full health-mark, we first began to try the aid of internal medicine, and put him on ter.daily doses of quinine and acid.

I would ask those who read these lines to think of a ghastly injury like this, in an aged man, then under treatment for gout. How does torn tissue, poisoned with gouty virus, usually heal? What action might we, in such a case, have expected the cerebral membranes to take on? How, in nine cases out of ten, would the resultant erysipelas have ended? I will not occupy space by answers. I simply have recorded the case as it already stands. Professor Lister's treatment has been fairly followed, and I leave the profession to say with what 
success. The anxiety of the profession on this subject is at once my reason and excuse for not waiting for the end; but, should that be otherwise than perfectly satisfactory, I will not fail to record and confess it.

I beg to acknowledge the kind liberality and readiness with which Mr. Newman left the case in my hands, notwithstanding he was the usual family attendant.

P.S. September 17 th. - The receipt of a proof-sheet affords me the opportunity of saying that, since the above lines were written (more than a month ago), the recovery has been, in point of fact, almost unretarded, except by frequent attacks of gout. The method in which the vessels of the dura mater vigorously pushed their way to the outer sur. face of the bone-becoming so superficial and distinct to the eye, that a touch with a pointed probe was sufficient to cause a tiny hæmorrhagewas a physiological fact that attracted the attention and admiration of both Dr. Rumsey and myself. The bone has been so nourished, that a mere shell (if so much) will die; and the artificial scalp, which Nature has nearly formed, will be an admirable substitute for the original outer covering of the cranium.

\section{REPORTS}

\section{or}

\section{MEDICAL AND SURGICAL PRACTICE IN THE HOSPITALS OF GREAT BRITAIN.}

\section{ST. MARY'S HOSPITAL.}

JAUNDICE : PNEUMONIA: SUDDEN DISAPPEARANCE OF JAUNDICE: ITS RETURN WITH THE DECLINE OF PNEUMONIA.

(Under the care of Dr. CheadLe).

F. B., a girl, aged 6 years, was suddenly seized with vomiting, which recurred for several days. She became languid and feverish, and lost appetite. The child did not complain of any pain, nor was any tenderness of her right side observed. On the third day, the skin was first noticed to be yellow. She was then placed under medical treatment, and for four weeks the jaundice gradually declined. During the fifth week, however, vomiting again came on, and she became more yellow than before. She was then admitted an out-patient under Dr. Cheadle's care, on January 6th, 1868. At this time, her skin was of a bright lemon colour, and she was very thin, having lost flesh from the commencement; but the tongue was clean, the pulse quiet and regular, and she seemed in fair general health, although languid and weak. The urine was reported to be bilious, and the stools clay-coloured. Three weeks' treatment with nitro-muriatic acid and occasional doses of grey powder, produced no change. She remained as deeply jaundiced as at first, and did not appear to gain much flesh or strength. On the 28th, four days after her last visit to the hospital, the mother came alone in great distress, stating that her child was much worse, having been seized two days before with high fever, and become very restless and short of breath, complaining of tenderness and pain in the left side of the chest. She mentioned also that on the following day the skin, which up to this time had retained its deep yellow tint unchanged, had suddenly regained its natural colour. The child was at once visited at home, and, on exami. nation of the chest, marked dulness was found at the upper part of the left lung, both in front and behind; under the clavicle the beating was intensely tubular, and at the upper part of the scapula fine crepitation was distinctly andible. The skin was excessively hot and pungent. The stools were stated to be still light coloured, and the urine dark, but none could be obtained for examination. As the mother had stated, with the exception of slight yellowness of the conjunctiva, the jaundice had entirely disappeared. Ten minims of antimonial wine in decoction of senega were ordered to be given every four hours, mustard poultices to the chest, and a liberal quantity of beef-tea and milk. The pneumonia gradually abated, but it was observed that, as the pulmonary inflammation subsided, the jaundice returned, and in the course of a fortnight the skin had again become decidedly yellow The pulse became very weak, and even irregular, for a few days, but from this time the patient steadily improved, and on the $25^{\text {th }}$ of February, a month after the first access of the pneumonia, the lung was found to have almost recovered its normal condition, and the only trace of jaundice which remained was a slight tinge of the conjunctiva. The child continued to enjoy good health when seen three months afterwards.

This case must be distinguished from those in which jaundice follows pneumonia of the lower lobe of the right lung, as a consequence of a supposed extension of inflammation to the liver. In the present instance, the jaundice was antecedent to the pneumonia, and the seat of the latter, in the upper lobe of the left lung, was far removed from the hepatic mischief.
Some general connection, yet unexplained, exists between jaundice and pneumonia. The fact, that many cases of pneumonia are preceded by hepatic disturbance and slight jaundice, has not escaped the notice of Dr. Parkes, who throws out the suggestion that the morbid liver may add something to the blood, which, in combination with a condition of hyperinosis, determines the localisation of the blood-disease, or excites by its irritating properties the inflammation of the lung. The case here recorded may help to furnish a clue to the true explanation of the reiation in which these two diseases stand to each other, which must be followed out by extended observation.

The sudden disappearance of jaundice on the advent of pneumonia, and its return with the decline of the pulmonary inflammation, may perhaps be explained by the intimate dependence in function between the two organs affected.

If the case were one of hepatic catarrh, as supposed, the condition would be as follows. Bile or sugar would be produced in the liver, probably in normal quantities; but, while the latter would pass into the blood-vessels and lymphatics without difficulty, the former would be hindered from escaping into the intestine by the tumid condition of the lining membrane of the ducts, clogged perhaps with viscid mucus. Instead, therefore, of a portion only of the bile being absorbed in the intestine, the whole quantity would be absorbed in the liver and pass into the blood-current. According to Liebig, the normal portion of bile absorbed in the intestine passes out by the lungs as carbonic acid or water; but the excessive quantity taken into the blood in the present case would not be oxidised as rapidly as it was supplied, and jaundice would be the result. Upon the advent of pneumonia however, the condition would be changed. The febrile state has been shewn by Bernard to arrest the formation of hepatic sugar. There would now, therefore, be a deficiency in the regular supply of fuel from the liver, and at the same time greatly increased combustion. The increased heat must be kept up by fuel from some source; and it seems probable that the first material seized on would be the excess of combustible elements of the bile present in the blood, a certain quantity of which is normally consumed in this manner, before the tissues suffered, as they do when there is a similar failure in the supply of carbon from the liver in other states of pyrexia, or in starvation. Not only, however, would the elements of the bile be more readily burnt up, but their quantity would probably originally be less, since the materials furnished by the waste tissues of the body would be fully oxidised at once in the blood-current, and therefore not available for the formation of bile. Thus the jaundice disappeared suddenly; but, as the fever subsided, the liver resumed its sugar-making function, and, more materials from waste tissue escaping full oxidation, nore bile would be secreted and pass into the blood-current, where it would not be oxidised so rapidly as before, and, accordingly, the jaundice gradually returned as the pneumonia declined.

\section{CENTRAL LONDON OPHTHALMIC HOSPITAL.}

\section{CASES OF INJURY OF THE EYE.}

\section{(Under the care of Mr. Hulme and Mr. Spencer Watson.)}

CASE I.-W. R., aged 16, applied on January 3rd, r868, in consequence of having received, the day previous, a sweeping blow orer the
cye with an old broom, wielded by one of his companions. Enormous swelling and ecchymosis had ensued, and, as it was impossible to examine the eye, he was admitted, and ordered cold lotions and aperients. Four days afterwards, the eye having been found to be uninjured, the boy was made an out-patient. On his attending, the seventh day afterwards, the eye was thoroughly examined. Complete ptosis was present; and, on the lid being lifted up and the movements of the eye tested, it was found that, in addition to the paralysis of the levator palpebræ, the boy could not move his eye upwards; the pupil was fully, although irregularly, dilated, and quite insensible to light; he could, however, see to read No. 2 Jæger, at ten inches, well. Two small wounds, at the extreme edge of the tarsal cartilage, were obscrved, but these had united. The other movements of the eye were perfect. Under a tonic treatment, the boy has been gradually improving; the levator and superior rectus have almost assumed their normal actions; and the iris, though still sluggish in its motor power, shows considerable action in the stimulus of light. The paralysis in this case would seem to have been due to the extensive blood-effusion and consequent pressure deep in the orbit, about the region of the lenticular ganglion, involving that branch of the third pair which supplies the levator palpebra and superior rectus; for, besides the injuries to the tarsal cartilage, there was no other external wound to be discovered.

CASE II. - J. W., aged 22, in the summer of 1859 received an injury to the right eye, from the explosion of a percussion-cap, a portion of which entered the cornea, and perforated the iris at its upper and inner 